\title{
Stairlifts
}

Janet Stowe

Most houses have the bedrooms, bathroom, and toilet on the first floor or higher. A stairlift enables a person who has problems climbing stairs to reach upper parts of the house with less difficulty.

\section{What is a stairlift?}

A stairlift is a device that transports a person up and down stairs, either sitting on a seat or standing on a platform; most have a seat. The electrically driven motor is usually under the seat on a platform. The platform rides up and down on a track that is fitted on the stairs. The stairlift is usually operated by a rocker (for example, a light switch) or toggle (as in computer games) switch by either the user or the carer. Other switch mechanisms are also available for those unable to operate the standard issue.

There are 26 different stairlifts currently available in the United Kingdom, most of which go up and down a straight staircase and cost about $£ 1500$. A few go round corners and this entails more complicated engineering, which is reflected in the cost-upwards of $£ 3000$. Occasionally where there is a half turn in the landing and a further two or three steps an adaptation can be made to use a straight stairlift. The life expectancy of a stairlift can be over 20 years. It is an expensive piece of equipment that also takes up quite a lot of space at the top and bottom of the stairs and on the staircase itself.

There are several ways in which people with difficulties in climbing stairs tackle this problem. Some go up and down on their behinds - a safe procedure if not a little uncomfortable - others may go up and down on all fours, descending backwards. As long as the patient (and carer) is happy to manage in this way there is usually no need or reason to install a stairlift. There are, however, cheaper alternatives to installing a stairlift: stair rails on each side of the staircase and strategically placed grab handles are often sufficient to enable disabled people to use stairs more easily. These may be at the top and bottom of the stairs and, where relevant, on a bend in the staircase. They can be provided by the social services department.

If a wheelchair is to be used a through floor lift may be more suitable as fire regulations need to be considered. There has to be a way of ensuring that the disabled person is not stranded upstairs. A through floor lift transports a patient in a wheelchair on a seat in the lift, or standing from one floor to another through a trap in the ceiling. The lift usually runs on two tracks fitted to the wall, and the lift is kept in the upper floor when not in use, leaving just the tracks in view.

\section{Rheumatology and}

Rehabilitation Research

Unit, School of Medicine, Leeds LS2 9NZ

Janet Stowe, DIP CoT, head research occupational therapist

Series edited by: Professor Graham Mulley.

BrMed f 1990;301:865-7 helps those caring for a disabled person (especially those suffering from multiple sclerosis or stroke) to be nearby and within earshot when help is needed during the night. To convert a living room into a bedroom with the possible addition of a commode is in most households inconvenient and unacceptable. Patients using stairlifts are usually delighted to be able to use

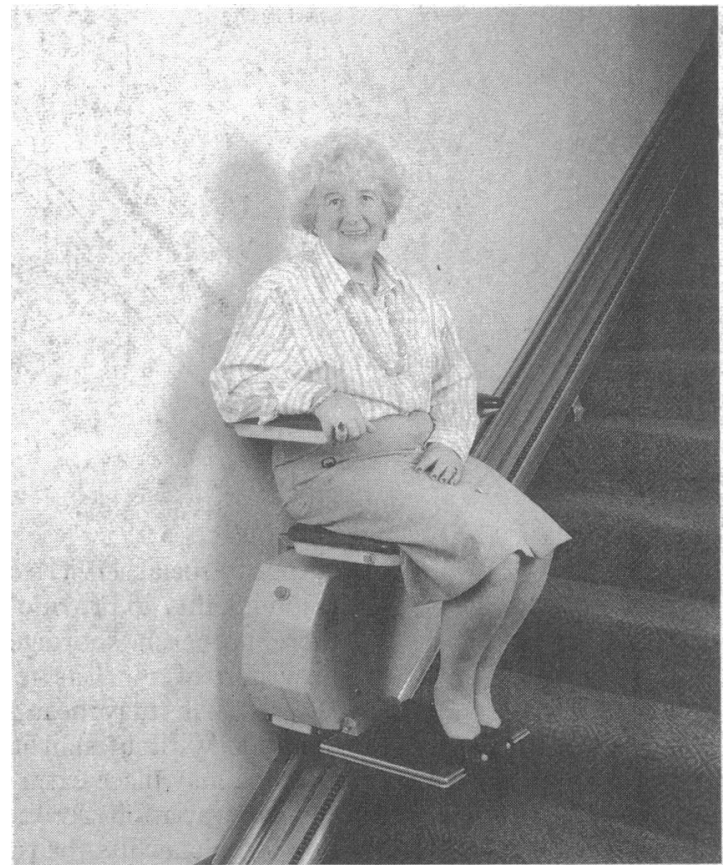

Stairlifts sit on a guiding rail, which is superficially mounted on to the staircase itself. They are as compact as possible, folding up to take about $25 \mathrm{~cm}$ of the stair width. The seat and footplate each fold, sometimes together, other times independently. The arms may fold up and, if so, will usually have a safety mechanism to prevent the stairlift from moving when the arm is upright. Sometimes the seat swivels (with a handle release mechanism) so that access on and off the seat can be made easier at the top and bottom of the stairs, where space may be limited. In case of a power failure or breakdown there is a hand wind facility to lower the stairlift down the staircase

the house normally and not be seen as the cause of disruption and loss of living space. They may also be thrilled at the new found ability to go up and down stairs with comparative ease. Stairlifts rarely break down and if they do so there is usually an established system to repair it speedily as it is recognised that a non-working stairlift means a stranded user.

\section{Who needs a stairlift?}

Many thousands of people who would otherwise be unable to use stairs use stairlifts. Those with a wide range of disabilities and difficulties such with arthritis, stroke, and coronary disease may benefit. Sometimes those with progressive disease, such as multiple sclerosis, are supplied with stairlifts, especially in the early stages. Otherwise through floor lifts are supplied in anticipation of transporting a wheelchair from ground floor to first floor. Handicapped children grow and become heavy for parents to carry up and down stairs. Depending on the disability either a stairlift or lift can be supplied.

\section{How to get a stairlift for your patient}

Doctors should consider aids and equipment whenever they have patients who have difficulty climbing the stairs. Stairlifts can be provided by the local 


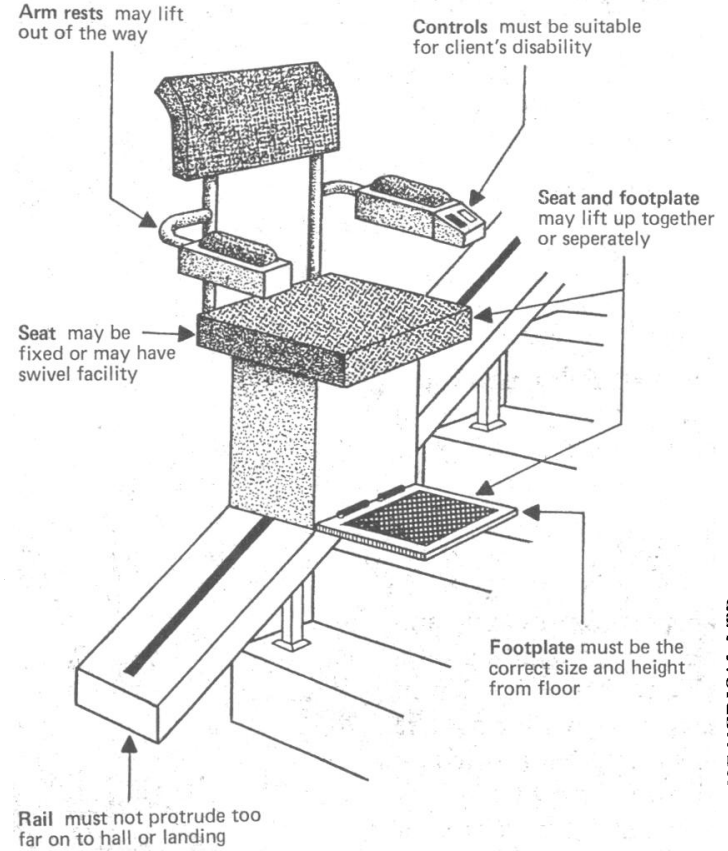

authority social services department, which has a legal responsibility to provide them when necessary. When there are cash shortages it is not uncommon for provision of stairlifts to be withheld or simply not allowed. This may mean that discharge from hospital is delayed. Without stairlifts managing disabled people at home may place extra strain on carers. As there are so many variations across the country in the method of providing stairlifts the time factor varies considerably from area to area between the assessment for a stairlift and the actual provision and installation. It may vary from two weeks to two years. This of course may lead to much anger and frustration by the patient and carers, who are already in a stressful situation and being stretched to their limit. Often many different staff are concerned, each responsible for a different aspect of provision and each giving different advice and information, leaving the patient and carers most confused. Nation wide we need key workers to whom people could relate and who could take overall responsibility for providing such equipment and answer all questions and queries, thus relieving the patients and carers of the stresses of conflicting information and advice.

The local social services department usually has an occupational therapist, who will visit the home and carry out an initial assessment of the patient's needs. This assessment is often carried out with a social services engineer. Together they can accurately assess the patient, the carers, and the home so that the most suitable stairlift is provided. The department of environmental health is usually involved in the acquisition of a stairlift (unless it is being bought privately) as the environmental health officer assesses patients for grants towards the cost of providing a stairlift. Sometimes the grant can be $75 \%$ with a top up of $15 \%$ by the social services and in cases of severe hardship a further $10 \%$ by social services. In other cases the family will have to find the difference. All areas of Britain differ in their financing of stairlifts. It would be sensible if all local authorities operated a uniform funding system. When a stairlift is no longer needed, depending on the practice of the local authority, it is sometimes removed from the home, stored, and reused elsewhere. Other times it may be the property of the user and the family to dispose of themselves. Stairlifts may be bought privately but even in these cases it is advisable first to seek the advice of the local social services occupational therapist; who will give an informed and unbiased opinion. The stairlift has to be serviced regularly to ensure its safety. The responsibility for this varies depending on local arrangements.

Assessing a patient for a stairlift is a specialised skill: not only does the patient's physical disability, shape, and size need to be assessed to determine the dimensions of the seat and the height of the footrest but also the prognosis of the disease, the patient's psychological state, and his or her ability to follow instructions must be established. In addition, the stairlift should be matched to the house in many aspects including access at the top and bottom of stairs and needs of other people living in the house. If the patient, carers, and home are correctly assessed the installation of a stairlift should make life easier and happier for all. There should be no problems to either patient or carer unless of course the medical conditions of either person should alter. In this case, the occupational therapist should be contacted again for reassessment. It may be that guidance on lifting and manoeuvring is all that is required.

If a patient has problems of mobility in the home and a stairlift would possibly be a helpful solution there are several ways of contacting the relevant staff, depending on the facilities of the district. Ideally, the occupational therapist at the patient's local social services office will be the person to contact. The therapist can be contacted directly by the general practitioner. If there is no such facility at the social services office, then try the occupational therapy department in the local general hospital, the main social services office, or the department of environmental health. In areas where there is a disabled living centre (of which there are 30 around the country) it is advisable to visit a centre where the patient and carers can try out a variety of stairlifts to discover preferences in design. The occupational

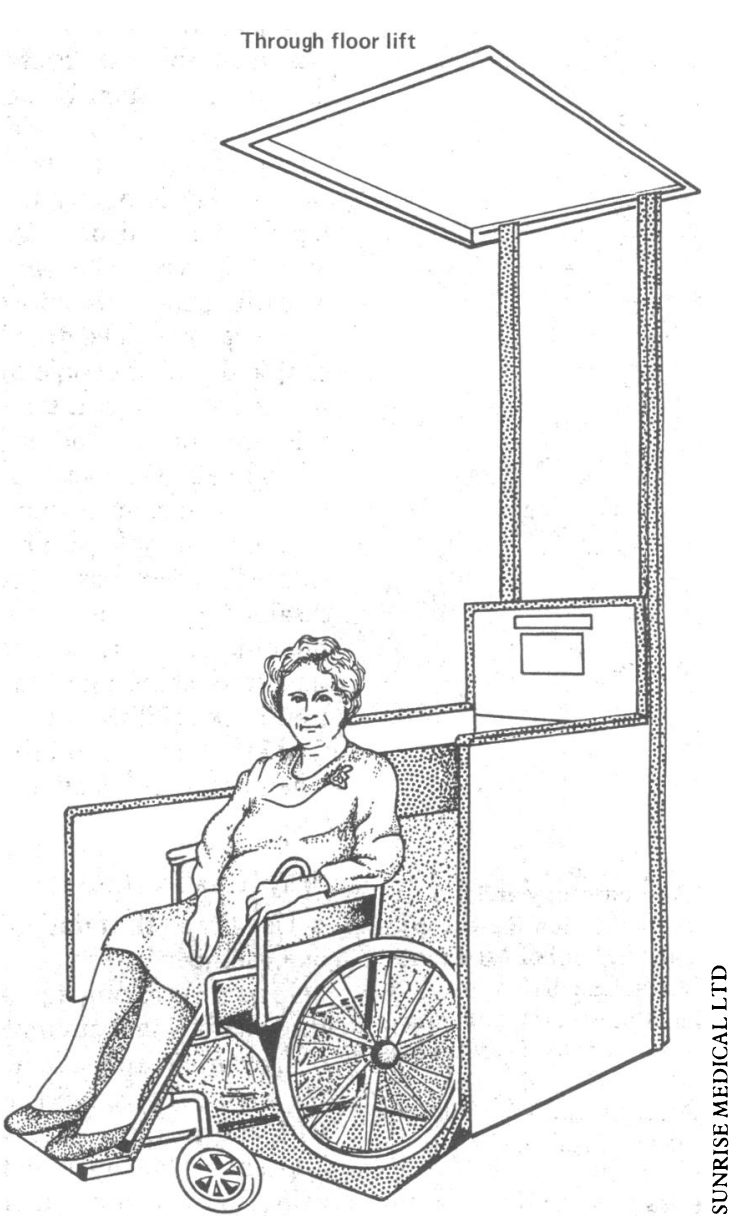


therapist will be able to tell you where the nearest centre is.

I thank Ruth Whittaker, of Leeds Social Services, for her help and Glynis Cooper and Barbara Dibb for their secretarial help.

Appendix

FURTHER READING

Stowe J. How to give your home a lift. Care Weekly 1988 Oct 7:28
Goodwill CJ, Chamberlain MA, eds. Rehabilitation of the physically disabled adult. London: Croom Helm, 1988.

Stowe J. Guide to the selection of the stairlifts. Available from Rheumatology and Rewabilitation Research Unit, 36 Clarendon Road, Leeds LS2 9NZ ( $£ 3.00$.)

Rehabilitation Research Unit, 36 Clarendon Road, Leeds LS2 9NZ. (£3.00.) institute. Specification for powered stairlifts. Leeds: British Bitute, 1979. (BS 5776.)

USEFUL ADDRESSES

Disabled Living Foundation, 380-384 Harrow Road, London W9 2HU (071 289

6111) W1 $(0716375400)$

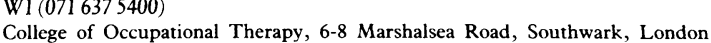
College of Occupational

\title{
USSR Letter
}

\section{Creating an association of Soviet doctors}

\author{
Michael Ryan
}

Rage and phrenzy will pull down more in half an hour, than prudence, deliberation and foresight can build up in a hundred years.

Those words of Edmund Burke, affirming the principles of order and continuity, may apply not only to major political institutions but also to those organisations which he called the "little platoons" of society. By the twentieth century these had come to include a range of professional associations, and in Russia, following the October revolution, these soon fell victim in the Bolsheviks' campaign to annihilate potential sources of opposition to the untrammelled exercise of state power. Today, however, a new generation of independent groups is being created thanks to the determination of individuals who act together as members of grassroots movements. This surely constitutes one of the most promising developments in a country emerging from the ruins of its totalitarian past.

How do Soviet doctors perceive their existing professional organisation known as the Union of Medical Workers? Set up by the Bolsheviks some 70 years ago, it embraces all categories of health care personnel, and throughout its history, like other unions, primarily served to convey the state's priorities to its membership. Under Gorbachev the concept of democratisation, along with that of glasnost, has been espoused as a means of furthering the radical transformation of the country's socioeconomic system. In theory, therefore, democratisation of the Union of Medical Workers would be the preferred strategy of a health service leadership which urgently needs to include rank and file doctors in the herculean task of improving the quality of medical care for the Soviet population.

A degree of support for that interpretation may be discovered in the record of the All-Union Congress of Doctors, which met at the Kremlin during October 1988. The first of its sort since 1925, the congress had been organised under an official aegis and shows that democratisation was being taken seriously in this sector of the economy. The first morning's session was attended by Gorbachev, along with other political leaders.

In the opening address by Yevgeni Chazov, the then USSR Minister of Health, no mention was made of the already current proposal to form an independent Association of Soviet Doctors. The first delegate who raised the issue was a youngish looking woman doctor from Leningrad's emergency aid service. In a brief generalised definition of such an association's functions $\mathrm{L} N$ Devotchenko said that it "would resolve all matters concerning the social and legal defence of doctors, contribute to raising the prestige of doctors and look after other matters which create pressing problems for us."

Presumably she thought that these functions could be undertaken effectively only by a new, completely autonomous body. Certainly the president of the union's central committee (Lidiya Novak) got a roasting from another delegate who, expressing a widely shared view, complained that her speech contained "nothing constructive for improving the conditions of work and daily life of medical workers." Later a Moscow cardiologist, Aleksandr Sviridov, wrote off the union as "having long ago discredited itself with the bureaucratism which flourished within it."

\section{Preliminary moves}

Taken as a whole, Sviridov's speech might be thought to convey the impression of a man who combines an incisively analytic mind with exceptional moral courage. ' Among other things he went on record as saying that the administrative command style of management persisted in the work of the health ministry and that no mechanism existed to guarantee democratisation in the restructuring of health care. $\mathrm{He}$ went on to propose a refinement of the idea of a doctors' association-namely, an association of practising doctors. The objective, in essence, was to create a sense of collective self determination and self confidence among doctors in the front line.

Despite the new political climate which favoured the formation of independent organisations of all sorts it seemed for some time as if an All-Union Association of Doctors would not come into being. Writing in Meditsinskaya gazeta some four months later Sviridov identified as a major inhibiting influence the sense of alienation among doctors which had been induced by the bureaucratisation of medicine in the Soviet Union. His pessimistic characterisation of the position was as follows:

Things have reached a point where a doctor essentially has ceased to be answerable for his work. He carries out the instructions of superordinate organisations without thinking and they bear the responsibility for his work. The most deplorable thing is that such a situation is convenient for many of us.

For Sviridov apparently the association would be at least as concerned to raise standards of competence and commitment as to defend clinicians vis à vis the administration and to improve terms and conditions of work. (Incidentally, he describes as a "common matter" the non-payment of doctors and nurses for additional duties.) Most importantly the association could take over responsibility (from the health ministry) for 